\title{
Design of Host based Intrusion Detection System using Fuzzy Inference Rule
}

\author{
Hari Om \\ Department of Computer Science \& Engineering \\ Indian School of Mines, Dhanbad \\ Dhanbad 826004,India
}

\author{
Alok Kumar Gupta \\ Department of Computer Science \& Engineering \\ Indian School of Mines, Dhanbad \\ Dhanbad 826004,India
}

\begin{abstract}
The security of a system is an important issue due to the latest advancements in information technology. Intrusion Detection Systems are used to identify the attacks and malicious activities in the computer systems. This paper discusses a new host based intrusion detection system for detecting changes in hardware profile using fuzzy inference rule. The proposed system is able to analyze and detect the unauthorized access in a computer system by generating a set of fuzzy IF-THEN rules with the help of frequent item set. These fuzzy inference rules are used to find the misuse of the system. The experiments of the proposed system are carried out on the system performance log.
\end{abstract}

\section{Keywords}

Intrusion Detection System (IDS), Fuzzy logic, System performance log, Fuzzy inference rules

\section{INTRODUCTION}

Due to technology emerges day by day, there is a need to have a security mechanism to protect the systems from unauthorised users and malicious activities. For this, the intrusion detection systems (IDS) are used. An intrusion detection system is a device or software application that collects information from a variety of network sources or computer systems for analysis in order to detect the signs of malicious activities. An intrusion is defined as a set of actions that attempts to compromise the integrity, confidentiality, or availability of the system resources [1]. Integrity refers to maintain and assure the accuracy and consistency of data over its entire life cycle. Confidentiality refers to maintain the secrecy of data into system so that unauthorized user cannot access. Availability refers to availability of information resources. There are two common approaches to develop an intrusion detection model: misuse detection model and anomaly detection model [2]. The misuse detection model refers to detection of intrusions that follow well-defined intrusion patterns. Every intrusion has some pattern e.g. number of packets, number of connection, bytes sent, duration etc. It matches the packets with the database of pattern. Whenever there is a match, alarms are raised. It is very useful in detecting known attack, but not suitable for unknown attacks. The anomaly detection model refers to detection performed by detecting changes in the patterns of utilization or behaviour of the system. Whenever there is any deviation from the normal behaviour activity, alarms are raised. Normal behaviour can be developed using different techniques such as statistical analysis, data mining algorithms, genetic algorithms, artificial neural network approach, fuzzy logic and rough set etc. The anomaly detection systems can detect new intrusions unlike the misuse detection systems. The IDSs can be network based or host based as far as the source of data is concerned. Network based IDS (NIDS) collects raw packets as the data source from the network and analyse for signs of intrusions. The host based IDS (HIDS) operates on information collected from within an individual computer system such as operating system audit trails, C2 audit logs, and System logs.

Fuzzy inference is the process of formulating the mapping from a given input to an output using fuzzy logic. This mapping provides a basis from which decisions can be made, or patterns are discerned. The process of fuzzy inference involves all of the pieces that are described in membership functions, logical operations, and fuzzy IF-THEN rules. The proposed work describes to design a host based intrusion detection system using fuzzy inference rules. The performance $\log$ of a computer system acts as input to proposed system. The input is divided into two subsets: one is called as training data and other as testing data. The training dataset is further classified into two subsets: abnormal and normal data. After that, perform data mining technique to select frequent items from each attribute in the abnormal data as well as normal data. These mined frequent items are used to find the important attributes of the input dataset, which in turn are used to develop a set of definite and indefinite rules using a deviation method. Then, indefinite rules must be ignored and definite rules are used to generate fuzzy inference rules by fuzzifying it in such a way that we obtain a set of fuzzy IF-THEN rules with consequent parts that represent as either normal or abnormal data. These rules are given to the fuzzy inference system to effectively learn[16][18]. In testing phase, the testing data is matched with fuzzy inference rules to detect abnormal and normal behaviour of data. In this proposed work, Mamdami fuzzy inference system is used which is implemented in MATLAB 7.5.

The remaining paper is organized as follows: Section 2 reviews the related work. Section 3 discusses our proposed work. The performance $\log$ analysis is given in section 4 . The experimental methodology and the results are discussed in section 5. Finally, the paper is concluded in section 6 .

\section{RELEATED WORK}

Several researchers have discussed different designs for developing intrusion detection systems. In the last couple of years, intrusion detection has received a lot of interest among the researchers since it is being widely applied for preserving the security within a network and computer systems. Denning has described a rule based intrusion detection system that can detect security violations attempted by outsiders to system penetrations and misuse by insiders [5]. In this system, the generated audit record is matched with the defined rules and checked for abnormal behaviour. Srinivasa et al. have presented a rule based intrusion detection system in which 
they use genetic algorithm to make IDS more efficient [6]. The genetic algorithm has been used to prune the best rules from the generated rule set. They use DARPA dataset for training and testing purpose. Siraj et al. discuss an intelligent alert clustering model for network intrusion analysis [7]. They use principal component analysis with expectation maximization technique to aggregate similar alerts and reduce the number of low quality alerts. Shanmugavadivu et al. use KDD Cup99 for their proposed anomaly based network intrusion detection system [8]. They use fuzzy logic for identifying the intrusion activities in a network. This system generates fuzzy IF-THEN rules and with the help of fuzzy decision module the system identifies the appropriate classification of the test data. Dhanalakshmi discusses a system in which the fuzzy logic is integrated with the data mining methods using genetic algorithm for intrusion detection [9]. This system uses data mining to extract rules and Mamdami fuzzy inference system to determine the behaviour of the test data. Om et al. have designed a PCA based anomaly detection system for outlier detection in a computer system [10]. They use principal component analysis (PCA) to reduce the dimensions of data recorded by the computer system (performance log). Bharti et al. have proposed an intrusion detection model in which they use feature selection algorithm to select the non-redundant attributes [11]. They use fuzzy K-mean clustering algorithm to calculate the membership of every data point and J48 classification techniques for assigning a cluster to a particular class. Han et al. describe an evolutionary neural network based intrusion detection system, which has good detection performance and also reduces the training time [12]. Om et al. discuss a neural network based model, which can detect changes in the hardware profile of a computer system [13]. They use back propagation network (BPN) for detection and reported that the very high and very low values of the learning rate have bad effect on the results.

\section{PROPOSED WORK}

Recently, several researchers have focused on fuzzy logic for developing an effective intrusion detection system. This paper also proposes a fuzzy logic based intrusion detection system for detecting the changes in hardware profile. The model of our system is shown in Fig. 1. The preprocessor generates the rules and provides them to fuzzy rules generator to generate

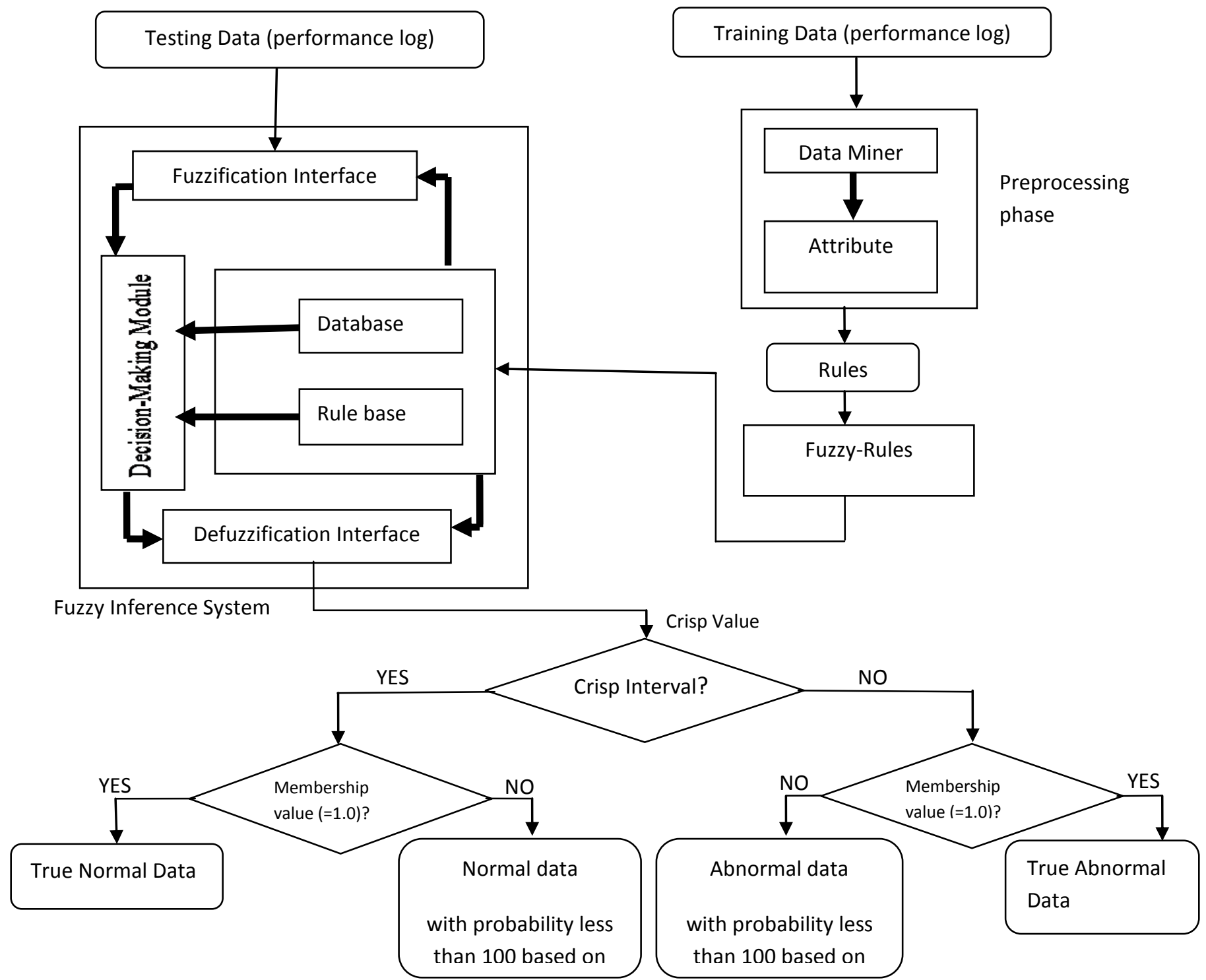

Fig. 1. Intrusion Detection System based on Fuzzy Inference rule 
fuzzy IF-THEN rules for the proposed system. A fuzzy inference system is used to generate the output for detection.

In this figure, a bold line denotes the interconnection inside the module and a normal line denotes the data flow in the proposed system. The different steps involved in the proposed system for intrusion detection are described as follows:
i. Preprocessing module
a. Data miner
b. Attribute selector
ii. Fuzzy rules generator
iii. Fuzzy inference system
iv. Finding behavior for a test input

\subsection{Preprocessing Phase}

The first component of our proposed system is preprocessing module. This module is responsible for accepting training data as system log and categorizes it into two classes: abnormal and normal data. These data are used to generate rules. The preprocessing module contains two sub-modules: data miner and attribute selector.

\section{a. Data miner}

The data miner integrates FP-Growth algorithm property to mine the frequent items in each attribute [3]. By considering the frequency of items in each attribute, the data miner identifies the frequent items by inputting sufficient support. The frequent items are identified for both the classes namely, abnormal and normal classes.

\section{b. Attribute Selector}

This module selects the suitable attributes from the input data as all the attributes are not useful for detection. For identifying the suitable attributes, the deviation method is used. Each class (abnormal and normal) is represented as

Class $_{i}=\left[A_{1}, A_{2}, A_{3}, \ldots \ldots . A_{n}\right]$, where $\mathrm{A}_{1}, \mathrm{~A}_{2, \ldots} \mathrm{A}_{\mathrm{n}}$ are the attributes in $i^{\text {th }}$ class. In our proposed system, the class ${ }_{1}$ refers to normal and class 2 to abnormal class. Each attribute $A_{j}$ contains items $I_{k}$ that have frequency greater than the minimum support.

$$
A_{j}=\left\{I_{k} ; 1 \leq k \leq m\right\} \text { and } \operatorname{support}\left(\mathrm{I}_{k}\right)>\min \text { support }
$$

Here, support $\left(\mathrm{I}_{\mathrm{k}}\right)$ is the frequency of $k^{\text {th }}$ item in $\mathrm{A}_{\mathrm{j}}$ attribute of class $_{\mathrm{i}}$. Then, for each attribute, the deviation range(D) $\{\mathrm{min}$, $\max \}$ of the frequent items is calculated as follows.

$$
\begin{array}{r}
D_{A_{j}}=\left\{f_{\min }, f_{\max }\right\} \text {, where } f_{\min }=\min \left[\operatorname{support}\left(\mathbf{I}_{k}\right)\right] \\
\text { and } f_{\max }=\max \left[\operatorname{support}\left(\mathbf{I}_{k}\right)\right]
\end{array}
$$

The attributes containing non-identical $\{\max , \min \}$ range for both the classes are chosen as effective attributes, which will give significant detection rate. The chosen attributes are used to generate rules for the proposed system. Compare the deviation range of the effective attributes for both abnormal and normal data to calculate intersection point. After that, intersection points are used to generate IF-THEN rules.

\subsection{Fuzzy Rules Generator}

The fuzzy rules are generated from the definite rules obtained from above step. The definite rules are the rules that contain only one classification label in THEN part. The fuzzy rules contain linguistic variables only, hence the membership functions are used to fuzzify the numerical values in definite rules. The triangular and trapezoidal membership functions are used in this step. For example, if an attribute 1 is $\mathrm{N}_{1}$, the data is abnormal; if an attribute1 is $\mathrm{N}_{2}$, the data is normal.
Here, $\mathrm{N}_{1}$ and $\mathrm{N}_{2}$ are linguistic variables. These fuzzy rules are given to Rulebase of the fuzzy inference system.

\subsection{Fuzzy Inference System}

This step describes the fuzzy logic system for finding the suitable class label of the input test dataset. In the proposed system, we use Mamdami inference system [14], which is based on Zadeh's paper on fuzzy algorithms for complex system and decision process [17]. In our proposed system, nine inputs and one output Mamdami fuzzy inference system with the centroid of area defuzzification strategy is used.

\subsection{Finding Behaviour for a Test Input}

For testing phase, a test data from the testing data is given to the Mamdami fuzzy inference system. It compares the input variable with the membership functions on the premises part to obtain the membership value for each linguistic label. The output of fuzzification interface is fed to the decision making unit which in turn compares that particular input with Rulebase. The output of knowledgebase is fed to defuzzification interface, which converts the fuzzy result into a crisp value. If the crisp value lies in the user defined intervals for respective behavior, the data can be classified as normal and abnormal. In our proposed system, if the crisp value is between 0 to 50 , i.e. $(0 \leq$ crisp value $\leq 50)$, the data is normal; and if the crisp value is between 50 to 100 , i.e. $(50<$ crisp value $\leq 100)$, the data is abnormal. If the membership value for a test data is 1.0 , the test data is either true normal or true abnormal.

\section{ALGORITHM}

Input: Performance log recorded by the computer system Output: Abnormal data or Normal data Assumptions:

a. Training data is divided into two classes: abnormal class and normal class.

b. Testing data contains abnormal data, normal data or both.

step 1: Training data is given as input to preprocessing module that contains data miner and attribute selector:

a) Data Miner extracts frequent itemsets in each attribute from both the classes: abnormal and normal classes.

b) Attribute selector selects effective attributes, which are suitable for rules generation.

c) With the help of effective attributes, IF-THEN rules are generated.

step 2: Rules obtained from preprocessor are given as input to fuzzy rules generator module.

step 3: Fuzzy rules generator generates fuzzy IF-THEN rules corresponding to each rule obtained in step 1 , and feeds it into rulebase of fuzzy inference system.

step 4: In database of fuzzy inference system, define membership function of fuzzy sets used in fuzzy rules.

step 5: Testing data is given as input to fuzzy inference system.

step 6: For each test data, fuzzy inference system generates a crisp value as an output.

step 7: If crisp value lies in the user defined intervals for respective behavior, the data can be classified as normal or abnormal. In our proposed system, if crisp value is between 0 to 50 , the data is normal 
and, if crisp value is between 50 to 100 , the data is abnormal.

step 8: If the membership value for a test data is 1.0 , the test data is true normal or true abnormal, otherwise test data has respective behavior with probability less than 1.0 based on the membership value.

\section{PERFORMANCE LOG ANALYSIS}

The performance $\log$ has been generated of patterns with errors and without errors. The proposed system has been applied to analyse the $\log$ and find the result.

\section{(a) Performance log}

The performance logs are generated by taking some of the process attributes for normal and abnormal behavior of the system. The performance of the personal computer can be measured by using the performance log. The hardware profile of the system that has been used in experiments as follows:

- Intel Core 2 Duo CPU @ $2.33 \mathrm{GHz}$

- 1024 MB RAM

- Microsoft Windows XP

\section{(b) Attributes used in performance log}

The used attributes for Performance Log analysis are as follows.

- \% committed byte in use: It is the ratio of memory committed bytes to the memory commit limit. The commit limit is determined by the size of the paging file.

- Available Mbytes: It is the amount of physical memory in Megabytes immediately available for allocation to a process or for the system use.

- System Driver Resident Bytes: It is the size (in bytes) of the pageable physical memory being used by device drivers.

- System Driver Total Bytes: It is the size in bytes of the pageable virtual memory currently being used by the device drivers.

- I/O Write Operations/sec: The rate at which the process is issuing write $\mathrm{I} / \mathrm{O}$ operations.

- File Control Operations/sec: It is the combined rate of file system operations that neither reads nor writes.
- File Data Operations/sec: It is the combined rate of read and write operations on all logical disks on the computer.

- File Write Operations/sec: It is the combined rate of the file system write requests to all devices on the computer, including requests to write data in the file system cache.

- Threads: It is the number of threads in the computer at the time of data collection.

\section{EXPERIMENT METHODOLOGY AND RESULT}

For experimental evaluation of the proposed system, the performance $\log$ of the computer system needs be generated. The steps for generating the performance logs are as follows:

- On the start menu, point to settings, point to Control Panel, double click Administrative Tools, and double click Computer Management.

- Explore performance Logs and Alerts, right click Counter Logs, and then click New Log Settings.

- Type a name for the counter log and then click OK.

- Click Add Counters.

- In the Performance object box, select a performance object that need be monitored.

- Counters added for experiment.

- On the General tab under Sample data every sampling interval of 15 seconds is configured.

- On the Log Files tab log files properties is configured as Comma delimited files that can be viewed later in reporting tools such as Microsoft Excel.

The training dataset has been divided into two subdatasets: normal dataset and abnormal dataset. Firstly, the normal dataset have been generated. Samples of normal dataset are shown in Table 1. After that, the abnormal dataset have been generated by disabling graphics driver, audio driver, and Ethernet driver. This generates the logs for the system performance that have been considered as intrusions. Samples of abnormal dataset are shown in Table 2. For testing dataset, we have taken normal data as well as abnormal data, i.e. mixed data. Samples of the testing patterns are shown in Table 3.

Table 1. Training Dataset (Normal dataset)

\begin{tabular}{|l|c|c|c|c|c|c|c|c|}
\hline $\begin{array}{l}\text { \% Committed } \\
\text { Bytes In } \\
\text { Use }\end{array}$ & $\begin{array}{l}\text { Available } \\
\text { MBytes }\end{array}$ & $\begin{array}{l}\text { System } \\
\text { Driver } \\
\text { Resident } \\
\text { Bytes }\end{array}$ & $\begin{array}{l}\text { System } \\
\text { Driver } \\
\text { Total } \\
\text { Bytes }\end{array}$ & $\begin{array}{l}\text { IO Write } \\
\text { Operations } \\
\text { /sec }\end{array}$ & $\begin{array}{l}\text { File Control } \\
\text { Operations } \\
\text { /sec }\end{array}$ & $\begin{array}{l}\text { File Data } \\
\text { Operations } \\
\text { /sec }\end{array}$ & $\begin{array}{l}\text { File Write } \\
\text { Operations } \\
\text { /sec }\end{array}$ \\
\hline 10.07679182 & 646 & 1114112 & 8830976 & 105.9535826 & 1407.184756 & 324.4265362 & 111.2242327 & $\begin{array}{l}\text { Threads } \\
535\end{array}$ \\
\hline 9.287402465 & 659 & 1118208 & 8830976 & 11.94779465 & 851.0300656 & 89.97557086 & 13.61648105 & 514 \\
\hline 9.271461777 & 688 & 1118208 & 8830976 & 20.24620835 & 147.1846067 & 72.46011408 & 20.24620835 & 507 \\
\hline 9.232098038 & 693 & 1118208 & 8728576 & 0.066668724 & 12.40038269 & 0.066668724 & 0.066668724 & 504 \\
\hline 9.207861687 & 692 & 1118208 & 8728576 & 20.06729463 & 157.6716006 & 68.86882176 & 20.06729463 & 499 \\
\hline 9.198427402 & 694 & 1118208 & 8728576 & 0.066668704 & 13.80042174 & 0.133337408 & 0.066668704 & 495 \\
\hline 9.070251261 & 698 & 1118208 & 8728576 & 16.80053295 & 144.1379057 & 65.66874981 & 20.06730324 & 486 \\
\hline 9.065859439 & 698 & 1118208 & 8728576 & 0.066668731 & 13.86709614 & 0.333343657 & 0.066668731 & 482 \\
\hline 9.061955597 & 700 & 1118208 & 8728576 & 20.66731268 & 146.0045638 & 66.33540684 & 20.66731268 & 481 \\
\hline 9.061630277 & 700 & 1118208 & 8728576 & 0.066668763 & 11.20035221 & 0.066668763 & 0.066668763 & 481 \\
\hline 9.059515696 & 700 & 1118208 & 8728576 & 20.06729652 & 145.8712452 & 65.93540286 & 20.06729652 & 480 \\
\hline 9.059190376 & 701 & 1118208 & 8728576 & 0.066668741 & 11.33368589 & 0.066668741 & 0.066668741 & 480 \\
\hline 9.247062766 & 680 & 1118208 & 8728576 & 27.80086509 & 532.8832487 & 249.8744421 & 147.4045869 & 491 \\
\hline
\end{tabular}




\begin{tabular}{|c|c|c|c|c|c|c|c|c|}
\hline 9.149792039 & 682 & 1118208 & 8728576 & 0.200006348 & 155.1382573 & 6.866884615 & 0.400012696 & 488 \\
\hline 9.150442679 & 699 & 1118208 & 8728576 & 20.06729462 & 144.2711813 & 65.73539035 & 20.06729462 & 489 \\
\hline 9.150442679 & 699 & 1118208 & 8728576 & 0.066668738 & 13.86709753 & 0.333343691 & 0.066668738 & 489 \\
\hline 9.144424257 & 698 & 1118208 & 8728576 & 20.06729919 & 150.7380846 & 66.06874918 & 20.06729919 & 486 \\
\hline 8.742165884 & 701 & 1118208 & 8728576 & 20.06729919 & 37.20116907 & 2.933425518 & 1.13336895 & 479 \\
\hline 8.73289426 & 701 & 1118208 & 8728576 & 20.06729501 & 149.9380282 & 67.33544174 & 20.06729501 & 475 \\
\hline 8.73289426 & 701 & 1118208 & 8728576 & 0.06666874 & 11.26701703 & 0.06666874 & 0.06666874 & 475 \\
\hline 8.728177117 & 702 & 1118208 & 8728576 & 20.06730434 & 146.6046587 & 66.00209735 & 20.06730434 & 473 \\
\hline 8.732406279 & 702 & 1118208 & 8728576 & 0.066668745 & 11.33368665 & 0.066668745 & 0.066668745 & 469 \\
\hline 8.721833374 & 702 & 1118208 & 8728576 & 20.06729527 & 143.2711546 & 65.66872373 & 20.06729527 & 463 \\
\hline 8.720857414 & 702 & 1118208 & 8728576 & 0.066668754 & 13.86710078 & 0.333343769 & 0.066668754 & 462 \\
\hline 8.715652291 & 701 & 1118208 & 8728576 & 20.06729895 & 153.271496 & 68.66883031 & 20.06729895 & 458 \\
\hline 8.71272441 & 702 & 1118208 & 8728576 & 0.066668742 & 11.26701732 & 0.066668742 & 0.066668742 & 456 \\
\hline 8.707844608 & 702 & 1118208 & 8728576 & 20.06729966 & 146.0712743 & 66.00208193 & 20.06729966 & 454 \\
\hline 8.707844608 & 703 & 1118208 & 8728576 & 0.066668741 & 11.33368595 & 0.066668741 & 0.066668741 & 454 \\
\hline 8.786246765 & 678 & 1118208 & 8728576 & 29.73427583 & 452.1476651 & 107.3367356 & 29.73427583 & 454 \\
\hline 8.73452086 & 703 & 1118208 & 8728576 & 20.20063344 & 855.2268176 & 436.4136848 & 20.20063344 & 453 \\
\hline 8.7343582 & 703 & 1118208 & 8728576 & 20.06729848 & 143.4045151 & 65.66873424 & 20.06729848 & 453 \\
\hline 8.746557706 & 702 & 1118208 & 8728576 & 0.06666875 & 23.40073138 & 3.333437518 & 0.06666875 & 453 \\
\hline 8.764287655 & 702 & 1118208 & 8728576 & 22.60071308 & 289.6758063 & 82.60260623 & 23.06739448 & 453 \\
\hline 8.747858987 & 702 & 1118208 & 8728576 & 0.066668763 & 11.33368974 & 0.066668763 & 0.066668763 & 453 \\
\hline 8.746557706 & 702 & 1118208 & 8728576 & 20.06729443 & 145.8045612 & 65.93539597 & 20.06729443 & 452 \\
\hline 8.746720366 & 702 & 1118208 & 8728576 & 0.066668774 & 11.33369156 & 0.066668774 & 0.066668774 & 452 \\
\hline 8.75387741 & 702 & 1118208 & 8728576 & 21.57819834 & 160.8374969 & 70.26234337 & 21.57819834 & 455 \\
\hline 8.752413469 & 702 & 1118208 & 8728576 & 0.066668746 & 11.26701807 & 0.066668746 & 0.066668746 & 455 \\
\hline
\end{tabular}

Table 2. Training Dataset (abnormal dataset)

\begin{tabular}{|c|c|c|c|c|c|c|c|c|}
\hline $\begin{array}{l}\% \\
\text { Committed } \\
\text { Bytes In } \\
\text { Use }\end{array}$ & $\begin{array}{l}\text { Available } \\
\text { Mbytes }\end{array}$ & $\begin{array}{l}\text { System } \\
\text { Driver } \\
\text { Resident } \\
\text { Bytes }\end{array}$ & $\begin{array}{l}\text { System } \\
\text { Driver } \\
\text { Total } \\
\text { Bytes }\end{array}$ & $\begin{array}{l}\text { IO Write } \\
\text { Operations } \\
\text { /sec }\end{array}$ & $\begin{array}{l}\text { File Control } \\
\text { Operations } \\
\text { /sec }\end{array}$ & $\begin{array}{l}\text { File Data } \\
\text { Operations } \\
\text { /sec }\end{array}$ & $\begin{array}{l}\text { File Write } \\
\text { Operations } \\
\text { /sec }\end{array}$ & Threads \\
\hline 7.423384034 & 700 & 1617920 & 2150400 & 102.1167592 & 1627.371182 & 312.9875432 & 107.081218 & 486 \\
\hline 7.148329421 & 705 & 1617920 & 2150400 & 31.36551108 & 517.8646084 & 150.0873073 & 31.76592186 & 484 \\
\hline 7.087332686 & 733 & 1617920 & 2150400 & 0.400010744 & 463.2791101 & 7.533535681 & 0.400010744 & 478 \\
\hline 7.091073819 & 735 & 1617920 & 2150400 & 20.06719968 & 152.1373743 & 68.66849061 & 20.06719968 & 475 \\
\hline 7.082778263 & 736 & 1617920 & 2150400 & 0.066668489 & 14.5337306 & 0.333342445 & 0.066668489 & 474 \\
\hline 7.083266237 & 736 & 1617920 & 2150400 & 27.80074732 & 578.8822277 & 98.26930826 & 29.40079033 & 474 \\
\hline 7.073832075 & 736 & 1617920 & 2150400 & 0.066599087 & 15.38438913 & 0.399594523 & 0.066599087 & 471 \\
\hline 6.970218954 & 739 & 1617920 & 2150400 & 17.53380821 & 144.0705686 & 65.6684452 & 20.06721016 & 465 \\
\hline 6.968592374 & 741 & 1617920 & 2150400 & 0.066668435 & 11.93364993 & 0.133336871 & 0.066668435 & 465 \\
\hline 6.963224662 & 741 & 1617920 & 2150400 & 20.06721729 & 144.5372993 & 65.93514254 & 20.06721729 & 464 \\
\hline 6.962086056 & 740 & 1617920 & 2150400 & 0.066668456 & 20.20054218 & 3.066748978 & 0.066668456 & 464 \\
\hline 6.964851241 & 742 & 1617920 & 2150400 & 3.400093518 & 58.93495431 & 27.66742765 & 3.400093518 & 461 \\
\hline 7.118400357 & 738 & 1617920 & 2150400 & 22.20059521 & 329.4088317 & 201.2720629 & 137.0703416 & 470 \\
\hline 7.040649851 & 739 & 1617920 & 2150400 & 0.80002152 & 148.6706658 & 4.533455281 & 1.0000269 & 467 \\
\hline 7.040487193 & 741 & 1617920 & 2150400 & 20.40055848 & 145.87066 & 66.3351493 & 20.40055848 & 467 \\
\hline 7.040487193 & 741 & 1617920 & 2150400 & 0.066668473 & 11.33364035 & 0.066668473 & 0.066668473 & 467 \\
\hline 6.622944207 & 744 & 1617920 & 2150400 & 16.667118 & 165.671153 & 67.00181438 & 20.80056327 & 457 \\
\hline 6.624733444 & 727 & 1617920 & 2150400 & 5.266809775 & 176.938141 & 27.467413 & 11.93365759 & 457 \\
\hline
\end{tabular}




\begin{tabular}{|r|r|r|r|r|r|r|r|r|}
\hline 6.622618891 & 727 & 1617920 & 2150400 & 20.06721418 & 143.7372551 & 65.66845838 & 20.06721418 & 456 \\
\hline 6.61952839 & 727 & 1617920 & 2150400 & 0.066668462 & 11.3336386 & 0.066668462 & 0.066668462 & 455 \\
\hline 6.619853705 & 744 & 1617920 & 2150400 & 20.06721714 & 145.3373202 & 66.00181053 & 20.06721714 & 455 \\
\hline 6.631077105 & 743 & 1617920 & 2150400 & 0.066668439 & 20.40054244 & 3.066748209 & 0.066668439 & 452 \\
\hline 6.62587205 & 743 & 1617920 & 2150400 & 20.06721692 & 144.6706336 & 65.93514132 & 20.06721692 & 450 \\
\hline 6.624570786 & 743 & 1617920 & 2150400 & 0.066668482 & 11.33364196 & 0.066668482 & 0.066668482 & 449 \\
\hline 6.614323335 & 744 & 1617920 & 2150400 & 20.06721429 & 143.203908 & 65.66845872 & 20.06721429 & 442 \\
\hline 6.605377147 & 744 & 1617920 & 2150400 & 0.066668464 & 13.06701891 & 0.333342319 & 0.066668464 & 436 \\
\hline 6.599684118 & 745 & 1617920 & 2150400 & 20.06721678 & 143.5372682 & 65.73513538 & 20.06721678 & 432 \\
\hline 6.599684118 & 745 & 1617920 & 2150400 & 0.066668473 & 11.26697186 & 0.066668473 & 0.066668473 & 432 \\
\hline 6.896209582 & 714 & 1626112 & 2150400 & 41.20111634 & 699.4189507 & 249.5400946 & 41.20111634 & 432 \\
\hline 6.634980896 & 745 & 1626112 & 2150400 & 7.000191124 & 582.6825754 & 289.3412331 & 7.000191124 & 431 \\
\hline 6.634980896 & 744 & 1626112 & 2150400 & 20.06721757 & 144.6706383 & 65.80180645 & 20.06721757 & 431 \\
\hline 6.644577716 & 744 & 1626112 & 2150400 & 0.066668477 & 19.73386925 & 3.066749951 & 0.066668477 & 430 \\
\hline 6.641161898 & 745 & 1626112 & 2150400 & 20.06721537 & 143.5372581 & 65.73513074 & 20.06721537 & 429 \\
\hline 6.641324556 & 744 & 1626112 & 2150400 & 1.266700927 & 17.26713369 & 1.800048686 & 1.266700927 & 429 \\
\hline 6.640185951 & 745 & 1626112 & 2150400 & 20.0672155 & 143.3372535 & 65.66846267 & 20.0672155 & 428 \\
\hline 6.639860635 & 744 & 1626112 & 2150400 & 0.066668472 & 19.66719923 & 3.06674971 & 0.066668472 & 428 \\
\hline 6.644415058 & 744 & 1626112 & 2150400 & 21.73392725 & 159.404356 & 70.66859782 & 21.73392725 & 430 \\
\hline 6.650433402 & 743 & 1626112 & 2150400 & 2.466734036 & 157.004288 & 16.60045338 & 2.933413449 & 430 \\
\hline
\end{tabular}

Table 3. Testing Dataset

\begin{tabular}{|c|c|c|c|c|c|c|c|c|}
\hline $\begin{array}{l}\% \\
\text { Committed } \\
\text { Bytes In } \\
\text { Use }\end{array}$ & $\begin{array}{l}\text { Available } \\
\text { MBytes }\end{array}$ & $\begin{array}{l}\text { System } \\
\text { Driver } \\
\text { Resident } \\
\text { Bytes }\end{array}$ & $\begin{array}{l}\text { System } \\
\text { Driver } \\
\text { Total } \\
\text { Bytes }\end{array}$ & $\begin{array}{l}\text { IO Write } \\
\text { Operations } \\
\text { /sec }\end{array}$ & $\begin{array}{l}\text { File Control } \\
\text { Operations } \\
\text { /sec }\end{array}$ & $\begin{array}{l}\text { File Data } \\
\text { Operations } \\
\text { /sec }\end{array}$ & $\begin{array}{l}\text { File Write } \\
\text { Operations } \\
\text { /sec }\end{array}$ & Threads \\
\hline 9.284637244 & 652 & 1097728 & 8830976 & 108.6147969 & 1339.254896 & 319.2395796 & 114.1205674 & 513 \\
\hline 9.278130841 & 657 & 1101824 & 8728576 & 23.3536425 & 819.6461272 & 109.0281481 & 23.3536425 & 510 \\
\hline 9.226730256 & 687 & 1101824 & 8728576 & 0.066668887 & 12.40041307 & 0.133337775 & 0.066668887 & 507 \\
\hline 9.223965035 & 688 & 1101824 & 8728576 & 20.06732944 & 145.1381269 & 65.66883553 & 20.06732944 & 504 \\
\hline 9.200379323 & 688 & 1101824 & 8728576 & 0.066668863 & 14.80048762 & 0.333344316 & 0.066668863 & 501 \\
\hline 9.189481098 & 688 & 1101824 & 8728576 & 20.66734708 & 159.4719168 & 69.46895373 & 20.66734708 & 496 \\
\hline 9.184438636 & 688 & 1101824 & 8728576 & 0.066668857 & 14.3338043 & 0.333344286 & 0.066668857 & 494 \\
\hline 9.064720818 & 691 & 1101824 & 8728576 & 16.80055114 & 143.8713863 & 65.66882091 & 20.06732497 & 488 \\
\hline 9.063094218 & 694 & 1101824 & 8728576 & 0.066668849 & 11.93372394 & 0.133337698 & 0.066668849 & 487 \\
\hline 9.064720818 & 678 & 1101824 & 8728576 & 24.8674805 & 307.8767425 & 90.0029455 & 28.86761141 & 487 \\
\hline 9.063419538 & 678 & 1101824 & 8728576 & 0.066668842 & 11.26703434 & 0.066668842 & 0.066668842 & 487 \\
\hline 9.06732338 & 678 & 1101824 & 8728576 & 20.13398502 & 152.8716148 & 69.20223991 & 20.13398502 & 487 \\
\hline 8.996403586 & 679 & 1101824 & 8728576 & 0.133337731 & 130.4043013 & 3.866794209 & 0.333344328 & 487 \\
\hline 9.157925043 & 676 & 1101824 & 8728576 & 25.20081934 & 363.5451531 & 224.2739584 & 140.0712207 & 495 \\
\hline 9.147840118 & 693 & 1101824 & 8728576 & 0.133337658 & 32.60105736 & 0.66668829 & 0.133337658 & 493 \\
\hline 9.148653419 & 693 & 1101824 & 8728576 & 20.40066379 & 144.2713609 & 66.00214754 & 20.40066379 & 492 \\
\hline 9.139056474 & 693 & 1101824 & 8728576 & 0.466681817 & 22.6007337 & 0.866694803 & 0.466681817 & 489 \\
\hline 8.738262042 & 696 & 1101824 & 8728576 & 18.06725269 & 162.0052548 & 66.73549795 & 20.73400586 & 480 \\
\hline 8.73305692 & 695 & 1101824 & 8728576 & 0.066668828 & 20.93401205 & 3.066766096 & 0.066668828 & 478 \\
\hline 8.73338224 & 695 & 1101824 & 8728576 & 20.06731572 & 143.2713006 & 65.66879066 & 20.06731572 & 478 \\
\hline 8.735171501 & 696 & 1101824 & 8728576 & 0.066668828 & 14.60047333 & 0.400012968 & 0.066668828 & 477 \\
\hline 8.731755639 & 696 & 1101824 & 8728576 & 20.0673133 & 143.2712833 & 68.73554822 & 20.0673133 & 473 \\
\hline 8.785596125 & 690 & 1101824 & 8728576 & 31.68734062 & 410.2442755 & 105.3349715 & 37.29014275 & 473 \\
\hline
\end{tabular}




\begin{tabular}{|r|r|r|r|r|r|r|r|r|}
\hline 8.770794058 & 690 & 1101824 & 8728576 & 20.80517306 & 163.5073216 & 70.95097479 & 20.80517306 & 471 \\
\hline 8.760546473 & 690 & 1101824 & 8728576 & 1.598386615 & 18.1150483 & 2.131182153 & 1.598386615 & 467 \\
\hline 8.75566667 & 694 & 1101824 & 8728576 & 20.06730937 & 144.6046313 & 65.73543867 & 20.06730937 & 464 \\
\hline 8.745907066 & 695 & 1101824 & 8728576 & 0.06666879 & 11.33369432 & 0.06666879 & 0.06666879 & 458 \\
\hline 8.990547823 & 663 & 1105920 & 8728576 & 38.33455603 & 673.8881606 & 227.5405908 & 38.33455603 & 459 \\
\hline 8.787710706 & 693 & 1105920 & 8728576 & 11.80038201 & 770.691616 & 331.8107416 & 14.46713501 & 459 \\
\hline 8.765914255 & 694 & 1105920 & 8728576 & 20.06730534 & 147.6713665 & 66.0687694 & 20.06730534 & 458 \\
\hline 8.777137801 & 693 & 1105920 & 8728576 & 0.066668812 & 20.93400694 & 3.066765348 & 0.066668812 & 458 \\
\hline 8.778601741 & 694 & 1105920 & 8728576 & 20.06730737 & 144.2712729 & 65.7354321 & 20.06730737 & 459 \\
\hline 8.774047259 & 694 & 1105920 & 8728576 & 0.066668791 & 14.20045253 & 0.333343956 & 0.066668791 & 457 \\
\hline 8.772095338 & 694 & 1105920 & 8728576 & 20.067307 & 143.2712384 & 65.66876211 & 20.067307 & 456 \\
\hline 8.771932678 & 694 & 1105920 & 8728576 & 0.066668779 & 11.26702366 & 0.066668779 & 0.066668779 & 456 \\
\hline 8.769167457 & 694 & 1105920 & 8728576 & 21.6673614 & 159.6717863 & 70.66893256 & 21.6673614 & 454 \\
\hline 8.769655437 & 694 & 1105920 & 8728576 & 0.066668788 & 11.33369404 & 0.066668788 & 0.066668788 & 454 \\
\hline 8.769004797 & 695 & 1105920 & 8728576 & 20.0673076 & 146.3380073 & 66.00210807 & 20.0673076 & 454 \\
\hline
\end{tabular}

For testing purpose, the testing dataset is given to the proposed system, which finds the behaviour of the input data as normal or abnormal. Results of some tested dataset are given in the form of a table (shown in Table 4). The last two columns denote the results of the tested dataset. The normal data is represented as $\mathrm{N}$ and the abnormal data as $\mathrm{A}$. In the last column, the membership value of each dataset is given for the respective behaviour. The membership value 1.0 denotes that it is completely member of normal or abnormal data.

Table 4. Result of test dataset of the proposed system

\begin{tabular}{|l|r|l|l|l|l|l|l|r|l|l|}
\hline $\begin{array}{l}\% \\
\text { committed } \\
\text { bytes in } \\
\text { use }\end{array}$ & $\begin{array}{l}\text { Available } \\
\text { Mbytes }\end{array}$ & $\begin{array}{l}\text { System } \\
\text { Driver } \\
\text { Resident } \\
\text { Bytes }\end{array}$ & $\begin{array}{l}\text { System } \\
\text { driver } \\
\text { total bytes }\end{array}$ & $\begin{array}{l}\text { IO write } \\
\text { operations } \\
\text { /sec }\end{array}$ & $\begin{array}{l}\text { File } \\
\text { control } \\
\text { operations } \\
\text { /sec }\end{array}$ & $\begin{array}{l}\text { File data } \\
\text { operations } \\
\text { /sec }\end{array}$ & $\begin{array}{l}\text { File write } \\
\text { operations } \\
\text { /sec }\end{array}$ & Threads & $\begin{array}{l}\text { Normal (N) } \\
\text { or } \\
\text { abnormal(A) }\end{array}$ & $\begin{array}{l}\text { Member- } \\
\text { ship value }\end{array}$ \\
\hline 8.7690047 & 695 & 1105920 & 8728576 & 0.0666687 & 11.533699 & 0.0666687 & 0.0666687 & 454 & $\underline{\mathbf{N}}$ & $\underline{\mathbf{1 . 0}}$ \\
\hline 6.5995214 & 729 & 1687552 & 2150400 & 0.7992243 & 33.167809 & 1.9314588 & 0.7992243 & 424 & $\underline{\mathbf{A}}$ & $\underline{\mathbf{1 . 0}}$ \\
\hline 8.7556666 & 694 & 1101824 & 8728576 & 20.067309 & 144.60463 & 65.735438 & 20.067309 & 464 & $\underline{\mathbf{N}}$ & $\underline{\mathbf{1 . 0}}$ \\
\hline 6.5915512 & 734 & 1687552 & 2150400 & 20.067295 & 143.40449 & 65.668725 & 20.067295 & 427 & $\underline{\mathbf{A}}$ & $\underline{\mathbf{1 . 0}}$ \\
\hline 9.1390564 & 693 & 1101824 & 8728576 & 0.4666818 & 22.600733 & 0.8666948 & 0.4666818 & 489 & $\underline{\mathbf{N}}$ & $\underline{\mathbf{1 . 0}}$ \\
\hline 7.1449136 & 728 & 1679360 & 2150400 & 5.2001596 & 197.13938 & 47.401454 & 5.2001596 & 469 & $\underline{\mathbf{A}}$ & $\underline{\mathbf{1 . 0}}$ \\
\hline 7.5839623 & 716 & 1105920 & 8728576 & 0.0666687 & 11.267024 & 0.0666687 & 0.0666687 & 450 & $\underline{\mathbf{A}}$ & $\underline{\mathbf{0 . 1 2}}$ \\
\hline 7.4222454 & 699 & 1675264 & 2150400 & 15.871385 & 206.06125 & 98.762694 & 15.871385 & 476 & $\underline{\mathbf{N}}$ & $\underline{\mathbf{0 . 2}}$ \\
\hline
\end{tabular}

Graphical results of the tested dataset of the proposed system are given below (refer Figs. 2 to 5):

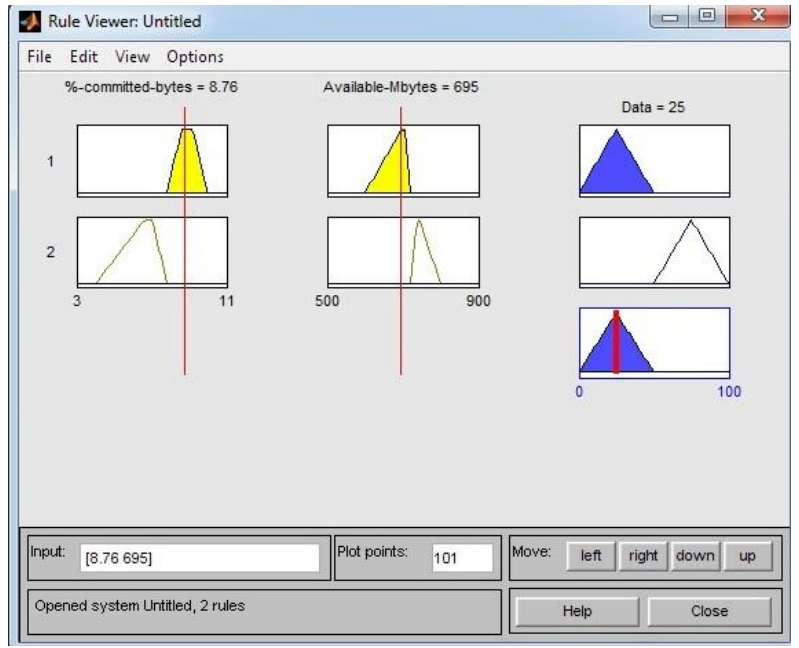

Fig. 2. Normal dataset with membership 1.0

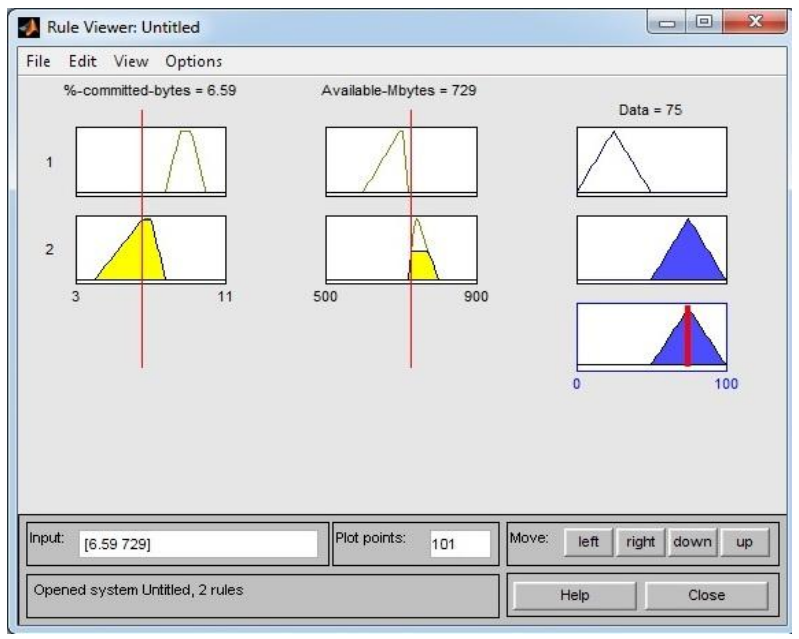

Fig. 3. Abnormal dataset with membership 1.0 


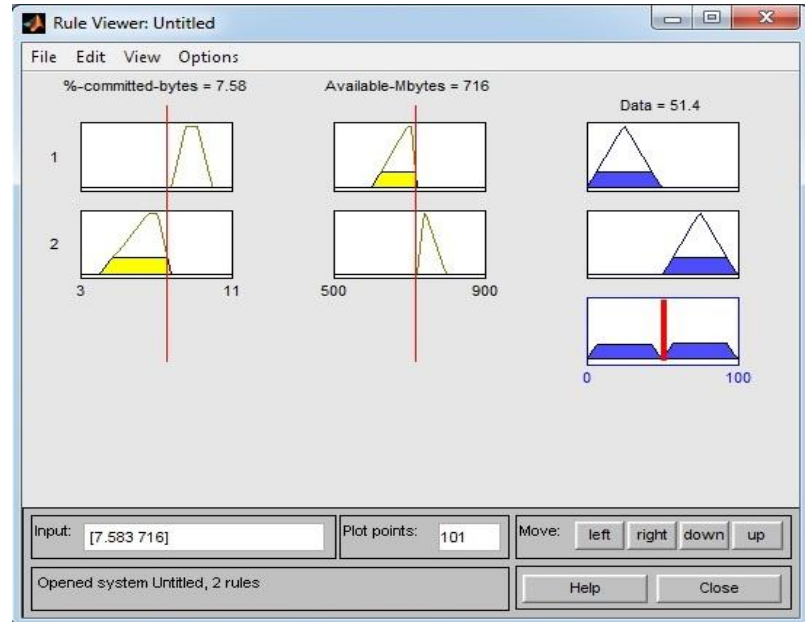

Fig. 4. Abnormal dataset with membership 0.12

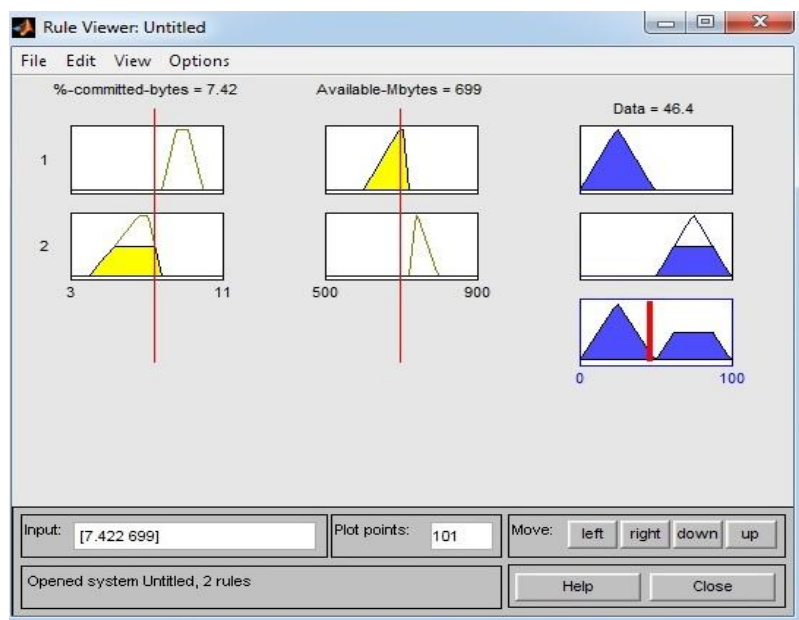

Fig. 5. Normal dataset with membership 0.2

\section{CONCLUSION}

Sometimes, a user attempts to change the hardware profile of a computer system without the knowledge of the administrator, this can be a sign of intrusion. This paper discusses an intrusion detection system using fuzzy logic, which can detect the changes in the hardware profile of a computer system. A Mamdami fuzzy inference system has been implemented to identify the accurate behavior of the generated system log. Mamdami fuzzy inference system works on the basis of fuzzy IF-THEN rules; so the fuzzy rules generator module has been used to generate the rules for all combinations of the selected attributes. System performance $\log$ of a computer system has been used to evaluate the performance of the proposed system. The experimentation results show that the proposed system can be applicable for detecting changes in hardware profile of a computer system.

\section{REFERENCES}

[1] Adetunmbi A. O., Zhiwei S., Zhongzhi S., Adewale O. S., "Network Anomalous Intrusion Detection using Fuzzy-Bayes," International Federation for Information Processing, Vol. 228, pp. 525-530, 2006.

[2] Biswanath, M., Todd L.H. AND Karl, N. L., "Network Intrusion Detection," IEEE Network, Vol. 8(3), pp. 2641, 1994.
[3] Han J., Pei J., Yin Y., Mao R., "Mining Frequent Patterns without Candidate Generation: A Frequent-Pattern Tree Approach," Data Mining and Knowledge Discovery, Vol. 8(1), pp. 53-87, 2004.

[4] Anderson J. P., Computer Security Threat Monitoring and Surveillance. Technical report, Fort Washington, PA, Apr. 1980.

[5] Denning D. E., "An Intrusion Detection Model," IEEE Trans. on Software Engineering, Vol. 13(2), pp. 222-232, 1987.

[6] Srinivasa K. G., Chandra S., Kajaria S., Mukherjee S., "IGIDS: Intelligent Intrusion Detection System Using Genetic Algorithms," World Congress on Information and Communication Technologies, pp. 852-857, 2011.

[7] Siraj M. M., Maarof M. A., Hashim S.Z.M., "Intelligent Alert Clustering Model for Network Intrusion Analysis," Int. J. Advance Soft Comput. Appl. Vol. 1 (1), pp. 33-48, 2009.

[8] Shanmugavadivu R., Nagarajan N. , "An Anomaly Based Netwok Intrusion Detection System Using Fuzzy logic," IJCSIS, Vol. 8(8), pp. 185-193, 2010.

[9] Dhanalakshmi Y., Babu I. R., "Intrusion Detection Using Data Mining Along Fuzzy Logic and Genetic Algorithms," IJCSNS, Vol. 8(2), pp. 27-32, 2008.

[10] Om H., Hazra T., "Design of Anomaly Detection System for Outlier Detection in Hardware Profile Using PCA," IJCSE, Vol. 4(9), pp. 1623-1632, 2012

[11] Bharti K., Jain S., Shukla S., "Fuzzy K-mean Clustering Via J48 For Intrusion Detection System," IJCSIT, Vol. 1(4), pp. 315-318, 2010.

[12] Han S. J., Cho S. B., "Evolutionary Neural Network for Anomaly Detection Based on the Behaviour of a Program," IEEE Trans. on Systems, Man and Cybernetics-Part B, Vol. 36(3), pp. 559-570, 2006.

[13] Om H., Sarkar T. K., "Neural network based intrusion detection system for detecting changes in hardware profile," Journal of Discrete Mathematics and Cryptography, Vol. 12(4), pp. 451-466, 2009.

[14] Mamdani, E.H. and S. Assilian, "An experiment in linguistic synthesis with a fuzzy logic controller," Int. Journal of Man-Machine Studies, Vol. 7(1), pp. 1-13, 1975.

[15] Stallings, W. Cryptography and Network Security Principles and Practices: Prentice Hall, 1998.

[16] Lamba,V.K., Neuro Fuzzy System, University Science press: 2008

[17] Zadeh, L.A., "Outline of a new approach to the analysis of complex systems and decision processes," IEEE Trans. on Systems, Man, and Cybernetics, Vol. 3(1), pp. 28-44, 1973.

[18] Cirstea, Dinu A., Khor, Mccormick M., Neural and Fuzzy logic control of Drives and Power System, Elsevier : 2002 